\title{
5-Hydroxytryptamine 1A Receptors, Major Depression, and Suicidal Behavior
}

\author{
William Pitchot, Michel Hansenne, Emmanuel Pinto, Jean Reggers, Sonia Fuchs, and Marc Ansseau
}

Background: Several lines of evidence suggest a clear relationship between serotonin (5-hydroxytryptamine, 5-HT) bypoactivity and suicidal behavior across several psychiatric diagnoses. Few data are available, however, regarding the possible specific role of 5-HT1A receptors in the biology of suicidality. Therefore, the aim of our study was to use a neuroendocrine strategy to test the bypothesis of a role for 5-HT1A receptors in the biology of suicidal behavior.

Metbods: Hormonal (adrenocorticotropic hormone [ACTH], cortisol, prolactin [PRL]) and temperature responses after administration of flesinoxan, a highly potent and selective 5-HT1A receptor full agonist, were assessed in 40 inpatients with major depression, divided into two subgroups (20 suicide attempters and 20 nonattempters), compared with 20 normal control subjects matched for gender and age.

Results: Compared with nonattempters, suicide attempters exhibited significantly lower PRL $(\mathrm{p}=.01)$, cortisol $(\mathrm{p}=.014)$, and temperature $(\mathrm{p}=.0002)$ responses. Prolactin $(\mathrm{p}=.007)$, cortisol $(\mathrm{p}=.04)$, and temperature $(\mathrm{p}=.00003)$ responses were also decreased in suicide attempters compared with normal control subjects. In contrast, we did not observe any significant differences in hormonal or temperature responses to flesinoxan between depressed patients without a history of suicide attempt and normal control subjects.

Conclusions: The present study tends to confirm the role of 5-HT and more specifically 5-HT1A receptors in the biology of suicidal behavior in major depression.

Key Words: Depression, suicidal behavior, serotonin, 5-HT1A receptors

S everal lines of evidence suggest a clear relationship between serotonin (5-hydroxytryptamine, 5-HT) hypoactivity and suicidal behavior across several psychiatric diagnoses. This serotonergic hypothesis is based on ante- and postmortem studies (Mann and Stoff 2001; Mann et al 1992). In vivo, most of the measures used to assess serotonergic function and in particular cerebrospinal fluid (CSF) measures of the metabolites of 5-HT represent presynaptic indices of serotonergic system activity and are unable to provide reliable information about the functioning of postsynaptic 5-HT receptors. In contrast, a neuroendocrine strategy might give an indirect index of central 5-HT activity at the postsynaptic receptor level and test the functional state of the serotonergic system. Currently, few studies have assessed the relationship between suicidality and hormonal responses to serotonergic probes (Pandey 1997). Moreover, neuroendocrine challenge studies performed in normal volunteers and psychiatric patients have provided large variability in their results, generally owing to the use of various serotonergic agonists exhibiting a different selectivity and requiring different doses and routes of administration (oral or intravenous). In the neuroendocrine assessment of the serotonergic hypothesis of suicidal behavior, fenfluramine has been the most widely used in depressed, schizophrenic, and personality disordered patients with a history of suicide attempt compared with control subjects (Coccaro et al 1989; Correa et al 2000; Duval et al 2001). Because fenfluramine is a 5 -HT releaser/reuptake inhibitor, however, the challenge assesses overall serotonergic function through activation of all the 5-HT receptor subtypes. Thus, fenfluramine is unable to provide data regarding which 5-HT receptors are

From the Psychiatric Unit, Centre Hospitalier Universitaire Sart Tilman, Liège, Belgium.

Address reprint requests to William Pitchot, M.D., Ph.D., CHU Sart Tilman, Psychiatric Unit, Liège B-4000, Belgium; E-mail: wpitchot@chu.ulg.ac.be. Received December 20, 2004; revised May 17, 2005; accepted May 27, 2005. implicated in the biology of suicidal behavior. Among all the 5-HT receptors, few data are available concerning the potential role of 5-HT1A receptors, which are clearly implicated in the pathophysiology of depression and in the mechanism of action of antidepressants. For these reasons, but also because of a lack of really specific probes for the other receptor functioning, we decided to study 5-HT1A receptors in relation to suicidal behavior.

In a recent study (Pitchot et al 2002), we emphasized the fact that flesinoxan, a highly potent and selective 5-HT1A full agonist, could be considered a reliable serotonergic probe for the study of serotonergic hypotheses of pathological conditions. Indeed, we showed a robust effect of flesinoxan $(1 \mathrm{mg})$ on neuroendocrine function and body temperature in a sample of male healthy volunteers, which tended to confirm a previous study (Seletti et al 1995). As a 5-HT1A receptor probe, flesinoxan has the advantage of avoiding several methodological problems encountered by the other 5-HT1A agonists, such as the lack of actual selectivity for 5-HT1A receptors or the availability of an oral form only (Pitchot et al 2002). In this context, the purpose of the present study was to assess hormonal and temperature responses to flesinoxan in inpatients with major depression and a history of suicide attempt compared with nonattempters and normal control subjects. More specifically, we wanted to test the hypothesis of a role for 5-HT1A receptors in the biology of suicidal behavior and to demonstrate the potential interest of the "flesinoxan test" as a biological tool in the assessment of suicide risk.

\section{Methods and Materials}

\section{Subjects}

The study was conducted among 40 inpatients with major depression according to DSM-IV criteria (American Psychiatric Association 1994), representing consecutive admissions to the Psychiatric Unit of the University Hospital of Liège, Belgium. The DSM-IV Axis I and Axis II diagnoses were made by two experienced psychiatrists on the basis of at least three clinical interviews. We excluded patients with psychotic symptoms and with a current diagnosis of alcohol and drug abuse or dependence (on the basis of the clinical interview of the patient and the family), 
Table 1. Clinical and Biological Characteristics of Depressed Patients, According to Their Suicide Attempt History, and Normal Control Subjects (Hormonal and Temperature Data are Expressed as Delta Peak Values)

\begin{tabular}{|c|c|c|c|c|}
\hline & Control Subjects & SA & NSA & $p$ \\
\hline Age (ys) & $38.6 \pm 11.8$ & $39.6 \pm 14.9$ & $43.2 \pm 10.4$ & ns \\
\hline $\operatorname{Sex}(M / F)$ & $12 / 8$ & $12 / 8$ & $12 / 8$ & ns \\
\hline Weight (kg) & $73.2 \pm 7.5$ & $72.9 \pm 7.0$ & $73.4 \pm 7.6$ & ns \\
\hline HAMD Scores & & $27.2 \pm 5.6$ & $26.5 \pm 7.1$ & ns \\
\hline Personality Disorders & & 8 & 6 & ns \\
\hline Melancholia & & 9 & 7 & ns \\
\hline Type of Suicide Attempt (V/NV) & & $8 / 12$ & & \\
\hline \multicolumn{5}{|l|}{ Hormones (Basal Values) } \\
\hline $\mathrm{ACTH}(\mathrm{pg} / \mathrm{mL})$ & $19 \pm 16$ & $18 \pm 19$ & $22 \pm 16$ & $\mathrm{~ns}$ \\
\hline Cortisol ( $\mu \mathrm{g} / \mathrm{L})$ & $118 \pm 52$ & $103 \pm 28$ & $115 \pm 75$ & ns \\
\hline PRL $(\mu \mathrm{IU} / \mathrm{mL})$ & $190 \pm 159$ & $160 \pm 90$ & $174 \pm 84$ & ns \\
\hline \multicolumn{5}{|l|}{ Flesinoxan Test } \\
\hline ACTH $(\mathrm{pg} / \mathrm{mL})$ & $73 \pm 105$ & $20 \pm 27$ & $30 \pm 24$ & .09 \\
\hline Cortisol ( $\mu \mathrm{g} / \mathrm{L})$ & $92 \pm 91$ & $22 \pm 38$ & $83 \pm 90$ & .03 \\
\hline PRL $(\mu \mathrm{IU} / \mathrm{mL})$ & $402 \pm 359$ & $151 \pm 132$ & $395 \pm 530$ & .03 \\
\hline Temperature $\left({ }^{\circ} \mathrm{C}\right)$ & $-.71 \pm .28$ & $-.14 \pm .34$ & $-.65 \pm .28$ & .00001 \\
\hline
\end{tabular}

SA, suicide attempters; NSA, suicide nonattempters; M, male; F, female; HAMD, Hamilton Depression Scale; V/NV violent vs. nonviolent suicide attempters; $\mathrm{ACTH}$, adrenocorticotropic hormone; PRL, prolactin.

bipolar disorder, and panic disorder. The patients were divided into two subgroups: suicide attempters and nonattempters. Individual characteristics of the patients are listed in Table 1. Both groups were matched for gender, age, and menopausal status (one patient in each group). Moreover, neuroendocrine tests were performed between days 3 and 12 of the menstrual cycle in premenopausal women (Tulandi et al 1987). The severity of depressive symptomatology was assessed by the 21-item Hamilton Depression Scale (HAMD) (Hamilton 1960) at the end of a drug-free period of at least 3 weeks ( 2 months in case of previous treatment with fluoxetine, lithium, anti-epilectics, or long-acting neuroleptics). Most of the psychotropic medications used by depressed subjects at intake included tricyclics, selective 5-HT reuptake inhibitors, and benzodiazepines in reasonable doses, allowing an easy tapering of the doses. Patients were only offered occasional low doses of a short-acting benzodiazepine. Overweight (35\% above ideal body weight) patients were excluded from the study. All patients were free of medical illness as evidenced by history, medical examination, electrocardiogram, chest X-ray, electroencephalogram, and routine laboratory tests.

A history of suicide attempt was based on interviews with patients and their families. Only suicide attempts with a real intent to die were recorded. The lethality of the attempt was assessed according to the Schedule for Affective Disorders and Schizophrenia lethality scale, referring to the most lethal lifetime suicide attempt (Spitzer and Endicott 1977). All patients with a history of suicide attempt had a lethality score higher than 4 . Suicide attempts were also classified as violent (hanging, drowning, deep cuts, and shooting) or nonviolent (drug overdoses and superficial wrist cuts). We also measured the time between the suicide attempt and the neuroendocrine investigation.

The control group included 20 healthy volunteers matched for gender, age, and menopausal status with the group of depressed patients. The subjects underwent a medical interview to exclude medical problems and personal or familial psychiatric disorders. They had a score less than 6 on the HAMD and less than 2 on item 1. The Ethics Committee of the University of Liège Medical School approved the protocol, and all subjects gave their informed consent.

\section{Neuroendocrine Procedure}

After an overnight fast, an indwelling catheter was inserted into a forearm vein at 8:30 AM. The first blood sample $(\mathrm{t}-30)$ was collected at 9:00 AM and was followed by six blood samplings at $t 0, t 15, t 30, t 60, t 90$, and $t 120$. The beginning of the flesinoxan injection took place at $\mathrm{t} 0$. Flesinoxan $(1 \mathrm{mg} / 70 \mathrm{~kg}$ body weight), diluted in saline solution to obtain $20 \mathrm{~mL}$, was injected intravenously over a period of $10 \mathrm{~min}$. All samples contained $10 \mathrm{~mL}$ of blood. They were centrifuged within 2 hours, and serum was immediately frozen and kept at $-18^{\circ} \mathrm{C}$ until analysis.

\section{Hormone Assays and Temperature Measure}

Prolactin (PRL), cortisol, and adrenocorticotropic hormone (ACTH) were measured by radioimmunoassay, according to previously published methods (Pitchot et al 2002). In particular, intra- and interassay coefficients of variation were $10.0 \%$ and $10.0 \%$, respectively, for prolactin, $4.3 \%$ and $8.3 \%$ for cortisol, and $4.1 \%$ and $3.3 \%$ for ACTH (Pitchot et al 2002). All samples were processed in duplicate within the same assay. Temperature was measured sublingually with an electronic thermistor probe at $\mathrm{t}-30, \mathrm{t} 0, \mathrm{t} 15, \mathrm{~T} 30, \mathrm{t} 60, \mathrm{t} 90$, and $\mathrm{t} 120$.

\section{Statistical Analysis}

Hormonal and temperature responses after flesinoxan administration were assessed by two different methods: by peak values after injection and by the areas under the curve situated between injection and the last blood sampling. Both analyses were performed with absolute values, as well as with differences related to basal level (relative values). In our analysis, we used the area under the curve relative values. Our data were not normally distributed, and a log transformation did not normalize the distribution. Therefore, to demonstrate differences between groups, we used a Kruskal-Wallis nonparametric test. In case of an overall effect, the Mann-Whitney $U$ test was then used for pairwise comparisons between groups. We also used the Spearman rank coefficient and Fisher exact test when appropriate. All values were expressed as means \pm SD, and for a clearer reading, hormonal and temperature data were presented as relative peak values. 


\section{Results}

Normal control subjects did not differ from depressed patients in terms of age or weight (Table 1). We did not observe any significant difference between suicide attempters and nonattempters in terms of HAMD scores or the distribution of personality disorder diagnoses. Moreover, baseline hormonal and temperature values were not significantly different between normal control subjects and both patient groups (suicide attempters and nonattempters) (Table 1). We observed a significant group effect in cortisol, PRL, and temperature responses to flesinoxan and a tendency for ACTH responses (Table 1). Compared with nonattempters, suicide attempters exhibited significantly lower PRL ( $p$ $=.01)$, cortisol $(p=.014)$, and temperature $(p=.0002)$ responses. Prolactin $(p=.007)$, cortisol $(p=.04)$, and temperature $(p=.00003)$ responses were also decreased in suicide attempters compared with normal control subjects. In contrast, we did not observe any significant differences in hormonal or temperature responses to flesinoxan between depressed patients without history of suicide attempt and normal control subjects. Hormonal and temperature responses to flesinoxan were not different between violent and nonviolent suicide attempters. The length of the period between the most lethal suicide attempt and the neuroendocrine investigation was not correlated with hormonal or temperature responses to flesinoxan.

\section{Discussion}

The present study tends to confirm the role of 5-HT and more specifically 5-HT1A receptors in the biology of suicidal behavior in major depression. Indeed, depressed patients with a history of suicide attempt exhibited significantly lower hormonal and temperature responses to flesinoxan compared with depressed patients who never attempted suicide and normal control subjects. We did not, however, observe any differences between nonattempters and normal volunteers, suggesting that a dysfunction in 5-HT1A receptor activity is not associated with depression as such but more to specific dimensions, like suicidality.

Hormonal and temperature responses to flesinoxan probably reflect the sensitivity of 5-HT1A receptors. Indeed, flesinoxan behaves as a very selective full agonist at the 5-HT1A receptor level, both pre- and postsynaptically (Pitchot et al 2004). Moreover, we recently showed that pindolol blocks ACTH, PRL, and oral temperature responses to flesinoxan but does not antagonize cortisol release and that ritanserin antagonizes PRL and ACTH responses without effect on cortisol and temperature responses (Hadrava et al 1995). Overall, these data suggest the specific interest of temperature response to flesinoxan to measure 5-HT1A activity at the hypothalamic level.

In this study, we failed to find a difference between depressed subjects without a history of suicide attempt and normal control subjects. This observation is in contrast with several studies assessing 5-HT1A function through the use of different neuroendocrine probes, such as ipsapirone, gepirone, or buspirone (Cowen et al 1994; Lesch et al 1990; Rausch et al 1990; Riedel et al 2002; Shapira et al 2000). In particular, an impaired temperature response to 5-HT1A agonists has been reported in some publications. In fact, these discrepancies could be due to the use of different 5-HT1A agonists or explained by the inclusion in most studies of more patients with a history of suicide attempt.

Our results are in agreement with previous studies supporting the involvement of 5-HT in the control of suicidal behavior and in particular the extensive literature regarding the relationship between low levels of CSF 5-hydroxyindoleacetic acid and history of suicide attempt. The more specific role of 5-HT1A receptors in the pathophysiology of suicidality has been assessed, particularly in postmortem studies, but with very controversial results. Cheetham et al (1990) measured 5-HT1 and 5-HT1A binding sites in brain tissue of 19 suicide victims suffering from depression before death compared with 19 gender- and age-matched control subjects and observed a significant decrease in the number of 5-HT1 receptors in the hippocampus without any change in the number or affinity of 5-HT1 or 5-HT1A receptors in frontal and temporal areas. This reduction in the number of hippocampus 5-HT1 receptors could be related to a decrease of 5-HT1A receptors, considered the prevailing subtype in hippocampus. In contrast, Stockmeier et al (1997) reported no significant differences between suicide victims with major depression and control subjects who died of natural or accidental causes in 5-HT1A receptors in area 10 of the right prefrontal cortex or the hippocampus. In another study, they observed an increase in 5-HT1A receptor binding in the most rostral part of the dorsal raphe nucleus of suicide victims compared with control subjects (Stockmeier et al 1998). Moreover, two studies found that the number of 5-HT1A binding sites did not differ significantly between suicide victims and control subjects (Arranz et al 1994; Lowther et al 1997); however, Arango et al (1995) studied a larger sample of suicide victims and reported that 5-HT1A receptor binding was higher in the prefrontal cortex. Lopez et al (1998) showed lower 5-HT1A messenger ribonucleic acid levels in the hippocampus of suicide victims with a history of affective disorders compared with control subjects. More recently, Arango et al (2001) found a reduction of 5-HT1A receptor distribution volume and a decrease of an index of the total number of 5-HT1A receptors in the dorsal raphe nucleus of suicide victims compared with the control group. They also observed that the 5-HT1A receptor binding capacity in the median raphe nucleus was lower in suicide victims compared with control subjects. As an explanation of these results, Arango et al suggested that a reduction of 5-HT1A autoreceptors could be an adaptative mechanism, whose function is to increase 5-HT activity. This interpretation could be applied to some of our data and in particular to the observation of a blunted temperature response to flesinoxan in suicide attempters compared with nonattempters and normal control subjects. In fact, temperature response to a 5-HT1A agonist could be due at least in part to the stimulation of somatodendritic 5-HT1A receptors. Indeed, in mice, the hypothermic response is mediated by cell body 5-HT1A receptors (Martin et al 1992; McAllister-Williams et al 2001), and in rats both pre- and postsynaptic receptors have been implicated (Bill et al 1991; Goodwin et al 1987; Millan et al 1993). In a recent publication, however (Hsiung et al 2003), evidence of impairment in the 5-HT1A signal transduction mechanisms has been reported in the occipital cortex of depressed suicide victims. If this effect holds true for 5-HT1A receptors in other parts of the brain, such as the hypothalamus or at the autoreceptor level, that could explain our observations.

The hypothesis of a link between stress-induced hypercortisolemia and 5-HT1A receptors activity could also constitute another explanation for our results. Indeed, several lines of evidence suggest that chronic stress could downregulate 5-HT1A receptors, particularly at the level of the hypothalamus, through an increase in circulating glucocorticoids (Lopez et al 1998). Many data support a major role for psychological and biological stress factors in the understanding of suicidal behavior. Psychosocial factors, such as stressful life events, have been well recognized as major risk factors of suicide. A relationship be- 
tween some biological aspects of stress, such as hypothalamicpituitary-adrenal (HPA) axis overactivity and suicide or suicide attempt, has been demonstrated in several studies but with controversy (Pitchot et al 1995, 2003). The discrepancies between studies (ante- or postmortem) could be explained by the fact that suicide attempt is a complex dimension compared with suicide completion. Both categories are parts of a large spectrum of suicidal behavior. In this context, we could hypothesize that significant HPA axis overactivity is associated with the risk of suicide as one extreme of this spectrum and not to other heterogenous aspects of the suicide-attempt dimension. Moreover, HPA axis overactivity could be found only in suicide attempters and completers with a recent or a lifetime history of severe psychosocial stress factors (Lopez et al 1999). This HPA axis overactivity hypothesis of suicidal behavior could also explain the apparent opposition between studies reporting an increase in some brain areas, such as prefrontal cortex, and studies reporting a decrease in other brain regions, such as hippocampus and hypothalamus. In fact, in relationship with the distribution of glucorticoid receptors expressed in the brain, corticosteroid could influence the sensitivity of 5-HT1A receptors differently in some areas versus others. In our study, hormonal and temperature responses to flesinoxan indirectly reflect the sensitivity of 5-HT1A receptors in the hypothalamic region, where type II glucocorticoid receptors are widely expressed (Dufourny and Skinner 2002).

In our study, the lack of a correlation between hormonal or temperature responses to flesinoxan and the time between the most lethal lifetime suicide attempt and the neuroendocrine investigation suggests that a dysfunction in hypothalamic 5-HT1A receptors could be a trait marker, according to several studies showing that the serotonergic activity is stable over time and possibly under the control of the 5-HT1A gene (Mann et al 1992; Seletti et al 1995). In humans, a recent positron emission tomography (PET) study failed to demonstrate a significant inhibitory effect of corticosteroids on 5-HT1A receptor binding, suggesting that 5-HT1A receptor downregulation could be primary, with a secondary increase of HPA axis activity (Montgomery et al 2001). Unfortunately, our study does not provide sufficient information to determine whether impaired 5-HT1A activity at the level of the hypothalamus in suicide attempters is genetically determined or a consequence of a long-lasting effect of corticosteroids.

Some limitations have to be considered in the interpretation of our data. A major pitfall in neuroendocrine studies is the possible inadequacy of a drug-free period of 3 weeks. Indeed, in animals, Li et al (1993) showed that chronic administration of fluoxetine blocked ACTH, corticosterone, and oxytocin responses to 8-hydroxy-2-(dipropylamino)tetralin, supporting the hypothesis of antidepressant-induced desensitization of postsynaptic 5-HT1A receptors in the hypothalamus. The downregulation of 5-HT1A receptors has also been demonstrated with paroxetine and venlafaxine in studies using the same paradigm (Gur et al 2000; Li et al 1997). In contrast, Newman et al (2000) failed to show an effect of clomipramine on the sensitivity of both pre- and postsynaptic 5-HT1A receptors at the level of the hypothalamus but showed a desensitization of hippocampal 5-HT1A receptors, suggesting that these effects are probably area-specific. Moreover, a recent PET study using the 5-HT1A antagonist way-100635 in patients with major depression showed that 5-HT1A receptor binding was reduced across several brain regions without change by selective 5-HT reuptake inhibitor treatment (Sargent et al 2000). Another problem is that we did not use a placebo challenge to control for a stress effect; however, this effect was limited by the insertion of the catheter $30 \mathrm{~min}$ before the first hormonal measure, and the influence of baseline values was controlled by expressing hormonal and temperature responses as $\Delta$ values. Moreover, because we did not measure flesinoxan plasma levels, some pharmacokinetic factors could explain some differences between groups. Another limiting factor is that hormonal and temperature responses to flesinoxan provide information about the sensitivity of 5-HT1A receptors at the hypothalamic level, and we do not know exactly to what extend a hypothalamically mediated response is informative regarding the activity of 5-HT1A receptors in other brain regions, such as hippocampus or prefrontal cortex. Finally, our data are limited to one subgroup of suicide attempters, those with a high lethality level; our purpose was to study subjects who were as close as possible to being suicide completers.

Another particular problem in the interpretation of our results is the observation of a significant difference between patients and control subjects for the stimulatory response of cortisol and not of ACTH. These data could be explained by the fact that ACTH is released in a pulsatile manner over the 24-hour cycle (Horrocks et al 1990), and it is therefore difficult to have a reliable measure of the pharmacological effect on ACTH stimulation. A second possible explanation could be a direct effect of flesinoxan on the adrenal gland; however, 5-HT receptors implicated in cortisol release at the level of the adrenal gland are 5-HT4 receptors subtypes, and it is unlikely to achieve a stimulation of 5-HT4 receptors with flesinoxan (Pitchot et al 2002).

Taking account of these limitations, the flesinoxan test seems to be a quite reliable tool for the assessment of 5-HT1A function in living and pathological conditions. Moreover, as an easy and minimally invasive technique, temperature response to flesinoxan could be used in clinical practice for the measure of suicide risk in depressed patients.

This work was supported by TRSM 5Fonds National de la Recherche Scientifique et Médicale grants, a grant from University of Liège and a grant from University Hospital of Liège (CHU).

American Psychiatric Association (1994): Diagnostic and Statistical Manual of Mental Disorders, 4th ed. Washington DC: American Psychiatric Association.

Arango V, Underwood MD, Gubbi AV, Mann JJ (1995): Localized alterations in pre- and postsynaptic serotonin binding sites in the ventrolateral prefrontal cortex of suicide victims. Brain Res 688:121-133.

Arango V, Underwood MD, Boldrini M, Tamir H, Kassir SA, Hsiung S-C, et al (2001): Serotonin 1 A receptors, serotonin transporter binding and serotonin transporter mRNA expression in the brainstem of depressed suicide victims. Neuropsychopharmacology 25:892-903.

Arranz B, Eriksson A, Mellerup E, Plenge P, Marcusson J (1994): Brain 5-HT1A, 5-HT1D, and 5-HT2 receptors in suicide victims. Biol Psychiatry 35:457463.

Bill DJ, Knight M, Forster EA, Fletcher A (1991): Direct evidence for a species difference in the mechanism of action of 8-OH-DPAT-induced hypothermia. Br J Pharmacol 103:1857-1864.

Cheetham SC, Crompton MR, Katona CLE, Horton RW (1990): Brain 5-HT1 binding sites in depressed suicides. Psychopharmacology 102:544-548.

Coccaro EF, Siever LJ, Klar HM, Mauer G, Cochrane K, Cooper TB, et al (1989): Serotonergic studies in patients with affective and personality disorders: Correlates with suicidal and impulsive aggressive behavior. Arch Gen Psychiatry 46:587-599.

Correa H, Duval F, Mokrani M-C, Bailey P, Trémeau F, Staner L (2000): Prolactin response to $D$-fenfluramine and suicidal behavior in depressed patients. Psychiatry Res 93:189-199. 
Cowen PJ, Power AC, Ware CJ, Anderson IM (1994): 5-HT1A receptor sensitivity in major depression. A neuroendocrine study with buspirone. $\mathrm{Br} J$ Psychiatry 164:372-379.

Dufourny L, Skinner DC (2002): Type II glucocorticoid receptor in the ovine hypothalamus: Distribution, influence of estrogen and absence of colocalization with GnRH. Brain Res 946:79-86.

Duval F, Mokrani M-C, Correa H, Bailey P, Valdebenito M, Monreal J, et al (2001): Lack of effect of HPA axis hyperactivity on hormonal responses to D-fenfluramine in major depressed patients: Implication for pathogenesis of suicidal behavior. Psychoneuroendocrinology 26:521-537.

Goodwin GM, DeSouza RJ, Green AR, Heal DJ (1987): The pharmacology of the behavioural and hypothermic responses of rats to 8-hydroxy-2-(d-npropylamino)tetralin (8-OH-DPAT). Psychopharmacology 91:506-511.

Gur E, Dremencov E, Van de Kar LD, Lerer B, Newman ME (2000): Effects of chronically administered venlafaxine on 5-HT receptor activity in rat hippocampus and hypothalamus. Eur J Pharmacology 436:57-65.

Hadrava V, Blier P, Dennis T, Ortemann C, de Montigny C (1995): Characterization of 5-hydroxytryptamine1 A properties of flesinoxan: In vivo electrophysiology and hypothermia study. Neuropharmacology 34:13111326.

Hamilton M (1960): A rating scale for depression. J Neurol Neurosurg Psychiatry 23:56-62.

Horrocks PM, Jones AF, Ratcliffe WA, Holder G, White A, Holder R, et al (1990): Patterns of ACTH and cortisol pulsatility over twenty-four hours in normal males and females. Clin Endocrinol 32:127-134.

Hsiung SC, Adlerscberg M, Arango V, Mann JJ, Tamir H, Liu KP (2003): Attenuated 5-HT1A receptor signalling in brains of suicide victims: Involvement of adenylyl cyclase, phosphatidylinositol 3-kinase, Akt and mitogen-activated protein kinase. J Neurochem 87:182-194.

Lesch KP, Mayer S, Disselkamp-Tietze J, Hoh A, Wiesmann M, Osterheider M, et al (1990): 5HT1A receptor responsivity in unipolar depression: Evaluation of ipsapirone-induced ACTH and cortisol secretion in patients and controls. Biol Psychiatry 28:620-628.

Li Q, Levy AD, Cabrera TM, Brownfield MS, Battaglia G, Van de Kar LD (1993): Long-term fluoxetine, but not desipramine, inhibits the ACTH and oxytocin responses to the 5 -HT1A agonist, $8-\mathrm{OH}-\mathrm{DPAT}$, in male rats. Brain Res 630:148-156.

Li Q, Muma NA, Battaglia G, Van de Kar LD (1997): A desensitisation of hypothalamic 5 -HT1A receptors by repeated injections of paroxetine: Reduction in the levels of $\mathrm{G}(\mathrm{i})$ and $\mathrm{G}(\mathrm{o})$ proteins and neuroendocrine responses, but not in the density of 5-HT1A receptors. J Pharmacol Exp Ther 282:1581-1590.

Lopez JF, Chalmers DT, Little KY, Watson SJ (1998): Regulation of serotonin $_{1 \mathrm{~A}}$, glucocorticoid, and mineralocorticoid receptor in rat and human hippocampus: Implications for the neurobiology of depression. Biol Psychiatry 43:547-573.

Lopez JF, Liberzon I, Vazquez DM, Young EA, Watson SJ (1999): Serotonin 1 A receptor messenger RNA regulation in the hippocampus after acute stress. Biol Psychiatry 45:934-937.

Lowther S, De Paermentier F, Cheetham SC, Crompton MR, Katona CL, Horton RW (1997): 5-HT1A receptor binding sites in post-mortem brain samples from depressed suicides and controls. J Affect Disord 42:199-207.

Mann JJ, McBride PA, Brown RP, Linnoila M, Leon AC, DeMeo M, et al (1992): Relationship between central and peripheral serotonin indexes in depressed and suicidal psychiatric inpatients. Arch Gen Psychiatry 49:442-446.

Mann JJ, Stoff DM (2001): A synthesis of current findings regarding neurobiological correlates and treatment of suicidal behavior. Ann N Y Acad Sci 836:352-363.

Martin KF, Phillips I, Hearson M, Prow MR, Heal DJ (1992): Characterization of 8-OH-DPAT-induced hypothermia in mice as a 5-HT1A autoreceptor response and its evaluation as a model to selectively identify antidepressants. Br J Pharmacol 107:15-21.
McAllister-Williams RH, Anderson AJ, Young AH (2001): Corticosterone selectively attenuates 8-OH-DPAT-mediated hypothermia in mice. Int J Neuropsychopharmacol 4:1-8.

Millan MJ, Rivet JM, Canton H, Le Maouille-Girardon S, Gobert A (1993): Induction of hypothermia as a model of 5-hydroxytryptamine1A receptor-mediated activity in the rat: A pharmacological characterization of the actions of novel agonists and antagonists. J Pharmacol Exp Ther 264:1364-1376.

Montgomery AJ, Bench CJ, Young AH, Hammers A, Gunn RN, Bhagwagar Z et al (2001): PET measurement of the influence of corticosteroids on serotonin-1A receptor number. Biol Psychiatry 50:668-676.

Newman ME, Gur E, Dremencov E, Garcia F, Lerer B, Van de Kar LD (2000): Chronic clomipramine alters presynaptic 5-HT1B and postsynaptic 5-HT1A receptor sensitivity in rat hypothalamus and hippocampus, respectively. Neuropharmacology 39:2309-2317.

Pandey GN (1997): Altered serotonin function in suicide: Evidence from platelet and neuroendocrine studies. Ann N Y Acad Sci 836:182-200.

Pitchot W, Hansenne M, Gonzalez Moreno A, Ansseau M (1995): The dexamethasone suppression test in violent suicide attempters with major depression. Biol Psychiatry 37:273-274.

Pitchot W, Reggers J, Pinto E, Hansenne M, Ansseau M (2003): Catecholamine and HPA axis dysfunction in depression: Relationship with suicidal behavior. Neuropsychobiology 47:152-157.

Pitchot W, Wauthy J, Hansenne M, Pinto E, Fuchs S, Reggers J, et al (2002): Hormonal and temperature responses to the 5-HT1A receptor agonist flesinoxan in normal volunteers. Psychopharmacology 164:27-32.

Pitchot W, Wauthy J, Legros JJ, Ansseau M (2004): Hormonal and temperature responses to flesinoxan in normal volunteers: An antagonist study. Eur Neuropsychopharmacol 14:151-155.

Rausch JL, Stahl SM, Hauger RL (1990): Cortisol and growth hormone responses to the 5-HT1A agonist gepirone in depressed patients. Biol Psychiatry 28:73-79.

Riedel WJ, Klaassen T, Griez E, Honig A, Menheere PP, van Praag HM (2002): Dissociable hormonal, cognitive and mood responses to neuroendocrine challenge: Evidence for receptor-specific serotonergic dysregulation in depressed mood. Neuropsychopharmacology 26:358-367.

Sargent PA, Kjaer KH, Bench CJ, Robiner EA, Messa C, Meyer J, et al (2000): Brain serotonin $_{1 \mathrm{~A}}$ receptor binding measured by positron emission tomography with [ $\left.{ }^{11} \mathrm{C}\right]$ WAY-100635. Effect of depression and antidepressant treatment. Arch Gen Psychiatry 57:174-180.

Seletti B, Benkelfat C, Blier P, Annable L, Glbert F, de Montigny C (1995): Serotonin $1 \mathrm{~A}$ receptor activation by flesinoxan in humans: Body temperature and neuroendocrine responses. Neuropsychopharmacology 13 93-104.

Shapira B, Newman ME, Gelfin Y, Lere B (2000): Blunted temperature and cortisol responses to ipsapirone in major depression: Lack of enhancement by electroconvulsive therapy. Psychoneuroendocrinology 25:421438.

Spitzer RL, Endicott J (1977): Schedule for Affective Disorders and Schizophrenia (SADS), 3rd ed. New York: New York State Psychiatric Institute, Biometrics Research.

Stockmeier CA, Dilley GE, Shapiro LA, Overholser JC, Thompson PA, Meltzer HY (1997): Serotonin receptors in suicide victims with major depression. Neuropsychopharmacology 16:162-173.

Stockmeier CA, Shapiro LA, Dilley GE, Kolli TM, Friedman L, Rajkowska G (1998): Increase in serotonin-1A autoreceptors in the midbrain of suicide victims with major depression: Postmortem evidence for decreased serotonin activity. J Neurosci 18:7394-7401.

Tulandi T, Lal S, Guyda H (1987): Effect of estrogen on the growth hormone response to the alpha-adrenergic agonist clonidine in women with menopausal flushing. J Clin Endocrinol Metabol 65:6-10. 